\title{
Fixed versus variable supply in the public provision of goods
}

\author{
Raluca Elena Buia* \\ Advanced School of Economics, University "Ca' Foscari” of Venice, Italy
}

\section{A R T I C L E I N F O}

\section{Article history:}

Received 8 October 2008

Accepted 4 June 2009

\section{Keywords:}

Corruption

Bribing

Discriminatory price auctions

Variable supply

\begin{abstract}
A B S T R A C T
Using discriminatory price auctions with variable supply, we explore a situation in which a corruptible public employee is in charge of producing and allocating a finite number of goods among consumers with uniformly distributed valuations. The negative effects of corruption are lower when the employee's task is to "provide at least $q_{0}$ goods" than when the employee is required to "provide exactly $q_{0}$ goods".
\end{abstract}

(c) 2009 University of Venice. Published by Elsevier Ltd. All rights reserved.

\section{Introduction}

Corruption is a complex phenomenon with many implications, both economic and social. Depending on the situations to which it is related, and on the causes that generate it, corruption can appear in a wide variety of forms, sometimes extremely different from one another. The immediate implication is that we cannot understand all corrupt behaviors and their effects using a unique model, hence the need for multiple tools in order to analyze the various forms of corruption. In this paper we use a model of discriminatory price auctions with variable supply to examine the behavior of a corruptible public employee in charge of providing goods and the implications of his corruptibility on the allocation of goods. We provide a solution for the simplified case of uniform distribution of both the marginal cost of producing the good and of the consumers' valuations for the good.

Most of the existing literature on corruption in the public sector examines situations in which bribes are asked or cases in which bribes are proposed but the public employee has the capacity to manipulate only the exit of a single object auction, as in the case of privatization. However, when a public employee is in charge of producing and allocating a number of goods, there are situations in which bribes are proposed by the potential consumers in order to influence the provider's decisions and the provider has some discretionality regarding the number of goods to produce. We consider that, if corruption is present in such situations, the best representation that we can give is by means of auctions. Depending upon how the public employee's official task is formulated, such cases can be described using different types of auctions: the traditional discriminatory-price auction if the supply is fixed, and the variable supply auction when the quantity required is only indicative as a minimum compulsory supply. In the first case, the public employee can only serve the consumers in decreasing order of grafts. In the second case, the public employee can increase the supply of services above what he is required in exchange for a bribe.

Several recent theoretical studies have been dedicated to auctions with variable supply, (Lengwiler, 1999; McAdams, 2006), but they have generally focused on uniform price auctions, while leaving the discriminatory price auctions mostly to empirical studies. Lengwiler (1999) extended his analysis also to discriminatory price auctions but he studied a very specific setup in which the bidders do not compete with one another in the auctioning process. In this paper we propose a model in which the auctioning process is generated by the fact that consumers are rivals and consequently "struggle" to get the goods.

\footnotetext{
* Corresponding address: Department of Economics, University “Ca’ Foscari” of Venice, Cannaregio 873, San Giobbe, 30121 Venice, Italy. Tel.: +39 329 8169228.

E-mail address: elenabui@unive.it.
} 
This model can also be used in a more general setup in which corruption is not present and the variable supply auction describes the behavior of a profit-maximizing private agent who has to make production decisions. However, the purpose of the present paper is to analyze certain corrupt behaviors in the public sector, which have not yet been fully characterized by the existing literature in the field and the variable supply auctions model is adequate for this purpose. In this case, corrupt public agents behave like private agents because they use the decision power with which they are invested, to achieve profit-maximization.

\section{The model}

A public employee is in charge of providing a service. As an example one can think of production licenses. Suppose the cost function of providing the goods is $C(q)=C_{0}+c \cdot \max \left\{0,\left(q-q_{0}\right)\right\}$. This should be interpreted in the following way: producing a quantity of the good $q$ lower than or equal to $q_{0}$ costs the public employee only a fixed $\operatorname{cost} C_{0}$, which is common knowledge, while any additional unit implies a constant marginal cost $c$. The marginal cost is private information. However, it is common knowledge that $c$ is uniformly distributed on the interval $[0,1]$. Hence, the cost of producing a quantity $q>q_{0}$ of the good is not verifiable and hence not contractible.

Suppose that the Government decides the number of goods, $q \geq q_{0}$, to be provided. It can choose between imposing the public employee to produce exactly a quantity $q_{0}$ (hereafter referred to as "fixed supply") or he can impose the employee to deliver at least $q_{0}$ goods (also referred to as "variable supply" in what follows). In exchange for his work, the provider is paid with a fixed transfer $W_{0}$ that guarantees him his reservation utility when producing $q_{0}$. We assume, without loss of generality, that the reservation utility of the employee is 0 . Then, if the utility function of the agent is given by $U=R-C$ (where $R$ stands for revenues), the transfer $W_{0}$ should equal $C_{0}$. Note that this utility function implicitly assumes that the employee's goal is the maximization of his net revenues. Consequently, the public employee is "sensitive" to side payments.

We assume that there are $N>q_{0}$ individuals demanding the good. Each of them asks for one unit. The individual $i$ attaches a value $v_{i}$ to the good, which is private information. We assume that $v_{i}$ is independently and identically distributed on the interval $[0,1]$ according to the distribution function $F\left(v_{i}\right)=v_{i}$.

Suppose that the public employee is corruptible and in exchange for a bribe he favors the persons who offer a higher graft when distributing the good. The employee can favor the bribe payers in two ways: (1) by increasing the supply of goods if the number of individuals offering him bribes superior to his marginal cost is higher than $q_{0}$ (when the Government announces variable supply); or (2) by serving the consumers in decreasing order of grafts.

In order to get a closed-form solution, thereafter we assume that there are two individuals who demand the $\operatorname{good}(N=2)$, and that the minimal compulsory quantity to be provided is one good $\left(q_{0}=1\right)$.

\section{Equilibrium and outcomes}

Fixed supply. The situation in which the Government announces that exactly $q_{0}$ production licenses are to be delivered is perfectly described by a traditional discriminatory price auction. We use the existent results, derived by Vickrey (1962), to characterize this situation.

Variable supply. Suppose that the public employee can increase the number of services delivered. Given that a quantity $q_{0}=1$ is always provided, the consumers compete in grafts for getting the good. However, in choosing their optimal strategy they take into account that, if their grafts are superior to the marginal cost $c$, it is optimal for the public employee to increase his supply by an extra unit. We model this by means of a discriminatory price auction with variable supply in which the individuals demanding the good are the bidders and the public employee is the auctioneer. The game has two stages: in the first stage the consumers simultaneously present their grafts offer to the public employee; in the second stage, the employee, after seeing the bids, decides whether to increase the quantity supplied. We solve the game by backward induction.

In the second stage, on the basis of the grafts offered by the bidders, the auctioneer (public employee) chooses to provide one or two units of the good. If the optimal strategy for a consumer is given by the bidding function $\beta(v)$, then the public employee's payoff function is:

$$
\pi= \begin{cases}W_{0}+\beta_{(1)}+\beta_{(2)}-C_{0}-c & \text { if he supplies } 2 \text { units } \\ W_{0}+\beta_{(1)}-C_{0} & \text { if he supplies } 1 \text { unit }\end{cases}
$$

where $\beta_{(j)}$ is the $j$-th highest bid.

Hence, the employee supplies two units when $\beta_{(2)} \geq c$. Consequently, the provider increases the number of goods delivered above $q_{0}=1$ if and only if the second highest graft is superior to his marginal cost. Otherwise, he only assigns the unique good to the highest bidder.

In what follows, we derive the symmetric equilibrium. To this end, we assume that the equilibrium bid function of the consumer $i$ 's rival, $\beta\left(v_{j}\right)$, is increasing and differentiable. The utility function of consumer $i$ with valuation $v_{i}$ is:

$$
u\left(v_{i}\right)= \begin{cases}v_{i}-b\left(v_{i}\right) & \text { if } b\left(v_{i}\right) \geq c \\ v_{i}-b\left(v_{i}\right) & \text { if } \beta\left(v_{j}\right)<b\left(v_{i}\right)<c \\ 0 & \text { if } b\left(v_{i}\right)<c \text { and } b\left(v_{i}\right) \leq \beta\left(v_{j}\right) .\end{cases}
$$


A consumer $i$ chooses $b\left(v_{i}\right)$ such as to maximize his expected profit:

$$
\max _{b\left(v_{i}\right)} P\left(b\left(v_{i}\right) \geq c\right)\left[v_{i}-b\left(v_{i}\right)\right]+P\left[b\left(v_{i}\right)<c\right] \cdot P\left[b\left(v_{i}\right) \geq \beta\left(v_{j}\right)\right]\left[v_{i}-b\left(v_{i}\right)\right]
$$

where $b\left(v_{i}\right)$ is the bid of consumer $i$. This can be rewritten as:

$$
\max _{b\left(v_{i}\right)}\left[v_{i}-b\left(v_{i}\right)\right]\left\{b\left(v_{i}\right)+\left[1-b\left(v_{i}\right)\right] P\left(\beta^{-1}\left(b\left(v_{i}\right)\right)>v_{j}\right)\right\}
$$

where $v_{j}$ is consumer $i$ 's rival valuation. Writing $b_{i}$ instead of $b\left(v_{i}\right)$ for simplicity, under our assumption in Section 2 , of uniform distribution of the consumers' valuations on the interval $[0,1]$, the first order condition is:

$$
-\left[b_{i}+\left(1-b_{i}\right) \beta^{-1}\left(b_{i}\right)\right]+\left(v_{i}-b_{i}\right)\left[1-\beta^{-1}\left(b_{i}\right)+\left(1-b_{i}\right)\left(\beta^{-1}\left(b_{i}\right)\right)^{\prime}\right]=0 .
$$

Taking into account that $\beta^{-1}\left(b_{i}\right)=v_{i}$, after simplifying and reordering, we obtain:

$$
\beta^{\prime}(v) v^{2}+2 \beta(v) \beta^{\prime}(v)(1-v)-\beta^{2}(v)+\beta(v)(v+1)-v=0 .
$$

This equation has four solutions, two of which are identical:

$$
\begin{aligned}
& \beta_{1}(v)=\frac{1}{3} v+\frac{2}{3}-\frac{1}{3} \sqrt{v^{2}-2 v+4} \\
& \beta_{2}(v)=\frac{1}{3} v+\frac{2}{3}+\frac{1}{3} \sqrt{v^{2}-2 v+4} \\
& \beta_{3,4}(v)=\frac{v}{v-1} .
\end{aligned}
$$

However, only one of them is an increasing function with $\beta(0)=0$, satisfying our (bidding function) requirements. ${ }^{1}$ The optimal bidding function is:

$$
\beta(v)=\frac{1}{3}\left(v-\sqrt{v^{2}-2 v+4}+2\right) .
$$

Given that:

$$
\begin{aligned}
& \beta^{\prime}(v)=\frac{1}{3}\left(1-\frac{v-1}{\sqrt{v^{2}-2 v+4}}\right)>0 \\
& \beta^{\prime \prime}(v)=-\frac{1}{\left(v^{2}-2 v+4\right)^{\frac{3}{2}}}<0
\end{aligned}
$$

it follows immediately that the bid is a strictly increasing and concave function on the interval $(0,1)$ and it is always lower than the valuation, for all $v \in(0,1)$.

The public employee supplies two units of the good if and only if:

$$
\frac{1}{3}\left(v-\sqrt{v^{2}-2 v+4}+2\right) \geq c .
$$

Proposition 1. There is a unique symmetric equilibrium and it is inefficient.

\section{Comparative analysis}

In what follows we analyze the differences between the two cases: (i) when the Government imposes the public employee to deliver exactly $q_{0}$ units (fixed supply) and (ii) when the Government announces variable supply. The main results for the case of fixed supply follow easily from known results in the traditional discriminatory price auctions. According to the work of Vickrey (1962), the bid of an individual who attaches value $v$ to the good is: $\beta^{F}(v)=\frac{1}{2} v$.

The central result, when comparing the fixed and variable supply, regards the bidding functions and is stated in the following proposition.

Proposition 2. The optimal bidding function in a discriminatory price, single-unit demand auction with variable supply is lower than in a first price sealed bid auction with fixed supply.

This result is easily proved by computing the difference between the optimal bids in the two cases,

$$
\beta^{F}(v)-\beta^{V}(v)=\frac{1}{6} v-\frac{2}{3}+\frac{1}{3} \sqrt{v^{2}-2 v+4}
$$

(where $\beta^{F}$ and $\beta^{V}$ stand for the bribe under fixed and variable supply respectively) which is strictly positive for any $v \in(0,1)$.

\footnotetext{
1 The functions $\beta_{2}(v), \beta_{3}(v), \beta_{4}(v)$ are decreasing in $v$ and hence do not fit our purpose.
} 
Proposition 2 implies that the competition between bidders is more fierce when the supply is restricted to a fixed quantity. In addition, from the first derivative of the above expression with respect to the valuation (which is strictly positive), we can conclude that this difference is increasing with the bidder's valuation, meaning that higher valuation bidders get more benefits from the variable supply.

A second result of the comparative analysis is related to the revenues/profits that the public employee (the auctioneer) can collect from bribes, under the two different scenarios. Although the single bids are lower, in a variable supply auction the seller has the advantage that he can collect bribes from both consumers. The revenue function of the seller in this case is given by:

$$
R^{V}\left(v_{(1)}, v_{(2)}\right)= \begin{cases}\beta\left(v_{(1)}\right) & \text { if } \beta\left(v_{(2)}\right)<c \\ \beta\left(v_{(1)}\right)+\beta\left(v_{(2)}\right) & \text { if } \beta\left(v_{(2)}\right) \geq c .\end{cases}
$$

Consequently, the profit that the provider expects from such an auction is:

$$
E \pi^{V}=\int_{0}^{\frac{4 c-3 c^{2}}{2-2 c}}\left(\int_{0}^{1} \beta(u) f_{(1)}(u) \mathrm{d} u\right) f_{(2)}(v) \mathrm{d} v+\int_{\frac{4 c-3 c^{2}}{2-2 c}}^{1}\left[\left(\int_{0}^{1} \beta(u) f_{(1)}(u) \mathrm{d} u\right)+\beta(v)-c\right] f_{(2)}(v) \mathrm{d} v .
$$

Based on the value of the marginal cost $c$, we can distinguish two cases:

I. Low marginal cost: $c \leq 1-\frac{\sqrt{3}}{3}$. (This implies that $\beta^{-1}(c) \leq 1$.)

Under our assumptions, this means that there is a positive probability that the second unit of the good is traded. Then, the expected profit of the public employee is:

$$
E \pi_{L}^{V}=\int_{0}^{1} \beta(u) f_{(1)}(u) \mathrm{d} u+\int_{\frac{4 c-3 c^{2}}{2-2 c}}^{1}[\beta(v)-c] f_{(2)}(v) \mathrm{d} v
$$

where " $L$ " stands for low cost.

Comparing this with the expected revenues raised by a first price sealed bid auction with supply fixed at one unit, we find that the variable supply auction leads to higher expected profits for the provider whenever $c \leq \bar{c} \approx 0.17$. $^{2}$ For $c>\bar{c}$, however, the fixed supply auction allows the seller to collect higher profits. The explanation stands in the fact that, when the marginal cost $c$ is low, the ex-ante probability of ex-post trading the second unit of the good is high:

$$
\operatorname{Pr}(\text { trade } 2)=\operatorname{Pr}\left(\beta\left(v_{(2)}\right)>c\right)=\frac{2-6 c+3 c^{2}}{2-2 c} .
$$

This probability is decreasing with $c$. Hence, the higher is the marginal cost, the lower is the probability that the provider sells both goods. Consequently, for high values of the marginal cost the seller expects to get more profit when supply is fixed to one unit because this makes the amount of every single bribe offered by the potential consumers higher. When $c$ is low, the potential profits from trading more goods compensate for the fact that the single bribes are lower than in the fixed supply case.

II. High marginal cost: $c>1-\frac{\sqrt{3}}{3}$. In this case, under variable supply, the second good is not traded because the secondhighest valuation consumer offers a bribe that is lower than the marginal cost for any $v_{2} \in[0,1]$ (for all such $c, \beta^{-1}(c)>1$ ). The seller expects to collect:

$$
E \pi_{H}^{V}=\int_{0}^{1} \beta(v) f_{(1)}(v) \mathrm{d} v=-\frac{1}{2} \ln 3-\frac{2}{3} \sqrt{3}+2 \approx 0.296 .
$$

Notice that for high marginal cost the revenues/profits that the seller expects to collect with variable supply are lower than those in an auction in which the supply is fixed to one good (in such a case $E \pi^{F}=\int_{0}^{1} \frac{v}{2} f_{(1)}(v) \mathrm{d} v=\frac{1}{3}$ ).

Summing up the above observations/considerations we can state the following corollary:

Corollary. The expected net revenue of the seller is higher under variable supply than under fixed supply for low levels of the marginal cost and lower for high levels of the marginal cost.

Finally, we briefly explore the difference in the level and the distribution of surpluses in the two cases. In a fixed supply auction the number of goods traded is established before the game starts. In a variable supply auction, instead, the number of goods traded is endogenously determined. The expected quantity provided is given by:

$$
E N=1+\int_{0}^{1} \operatorname{Pr}(\beta(v)>c) f_{(2)}(v) \mathrm{d} v \approx 1.154
$$

where $\int_{0}^{1} \operatorname{Pr}(\beta(v)>c) f_{(2)}(v) \mathrm{d} v$ defines the ex-ante probability that two goods are delivered. The ex-ante expected level of social welfare amounts to:

$$
E W_{c}^{F}=\int_{0}^{1} v f_{(1)}(v) \mathrm{d} v-C_{0}=\frac{2}{3}-C_{0}
$$

\footnotetext{
2 A more precise value for the threshold $\bar{c}$ is 0.16999019 .
} 
with fixed supply, while under variable supply it is:

$$
E W_{c}^{V}=\int_{0}^{1} v f_{(1)}(v) \mathrm{d} v-C_{0}+\int_{0}^{1}\left[\int_{0}^{\beta\left(v_{(2)}\right)}(v-c) d c\right] f_{(2)}(v) \mathrm{d} v=1-\frac{1}{4} \ln 3-C_{0} \approx 0.725-C_{0} .
$$

From a social or consumers ${ }^{3}$ perspective, the variable supply auction is better than the fixed supply because it leads to higher levels of expected trade and welfare. From the seller's point of view, which of the two auctions is better depends on the level of marginal cost $c$.

\section{Conclusions}

When evaluating the outcomes of fixed supply and variable supply auctions from the auctioneer's point of view, the range of the marginal costs is very important. Low values of the marginal cost make the variable supply auction preferable. This is because, compared with a traditional auction, the expected profit from selling an additional good is higher than the unrealized revenues from receiving a lower bid for the first good. On the other hand, high values of the marginal cost make the fixed supply auction a better choice for the following reasons: (i) if the second good is sold, the profits from trading may not be high enough to compensate for the decrease in bids with respect to the fixed supply case; or (ii) if the second good is not traded at all, under fixed supply the seller would be better because he receives more in exchange for the first unit.

From a social point of view the variable supply auction is always preferred.

\section{Acknowledgements}

I am grateful to my PhD advisor, Professor Marco LiCalzi, for his valuable suggestions and support.

\section{References}

Lengwiler, Y., 1999. The multiple unit auction with variable supply. Economic Theory 14, 373-392. McAdams, D., 2006. Uniform price auctions with adjustable supply, MIT Working Paper, 4618-06.

Vickrey, W., 1962. Auctions and bidding games. Recent Advances in Game Theory 15-29.

3 The consumers expect a surplus of:

$$
E S_{c}^{F}=\int_{0}^{1}[v-b(v)] f_{(1)}(v) \mathrm{d} v-C_{0}=\frac{1}{3}-C_{0}
$$

under fixed supply and:

$$
E S_{c}^{V}=\frac{3}{8} \ln 3-C_{0} \approx 0.412-C_{0}
$$

under variable supply. 